\title{
Labour market fluidity and employment outcomes in Colombia: evidence from employer-employee linked data ${ }^{1}$
}

\author{
Leonardo Fabio Morales and Daniel Medina
}

\begin{abstract}
Labour market flexibility has been a traditional subject of study in labour economics; recent literature has focused on the related concept of fluidity, broadly understood as the mobility of workers and jobs in the labour market. Here, we compute standard measures of fluidity for the Colombian urban labour market, finding evidence of increased fluidity, especially after 2010. Recent developments in equilibrium unemployment models predict, in general settings, a negative relationship between some fluidity measures and the equilibrium rate of unemployment. Recent literature on worker and job flows has identified benign aspects of fluidity, in that fluid labour markets are expected to have shorter average unemployment duration. We find evidence for a positive effect of fluidity on different employment and occupation indices using instrumental variable regression models that exploit variations in labour market outcomes and fluidity measures over time.
\end{abstract}

\section{Keywords}

Employment, labour market, human resources, labour mobility, measurement, employment statistics, Colombia

\section{JEL classification}

J60, J63, J11

\section{Authors}

Leonardo Fabio Morales is a researcher with the Labour Market Analysis Group of Banco de la República (central bank) of Colombia. Email: Imoralzu@banrep.gov.co.

Daniel Medina is a trainee professor with the Department of Economics of EAFIT University, Colombia. Email: dmedin17@eafit.edu.co.

\footnotetext{
1 The authors are grateful for comments from Christian Posso, Carlos Medina, Lina Cardona and the members of the Labour Market Analysis Group of Banco de la República of Colombia (http://investiga.banrep.gov.co/es/grupos-de-investigacion/ grupo-de-analisis-del-mercado-laboral-gamla). An earlier version of this article in included as a working document in Morales and Medina (2016).
} 


\section{Introduction}

A recent body of labour economics literature has dealt with the degree of dynamism in developed countries' labour markets. The loss of dynamism in the United States labour market during the last three decades has been particularly well documented (Bjelland and others, 2011; Molloy and others, 2016; Davis and Haltiwanger 2014; Hyatt and Spletzer 2013). The concept of fluidity has been used in this literature to capture the ability of an economy to mobilize workers and jobs across firms, economic sectors and labour markets. Fluidity has become an important topic in the study of the labour market recently because there is evidence for the adverse consequences of a reduction in dynamism (Davis and Haltiwanger, 2014; Molloy and others, 2016). Despite the importance of this topic, very little is known about labour market fluidity in developing economies and its consequences for labour market outcomes.

In this study, we compute worker reallocation rates (WR), job reallocation rates (JR) and churning rates $(\mathrm{CR})$, which are the most standard fluidity measures used in the literature; these three rates are relative measures of what the literature on labour market fluidity calls worker, job and churning flows, respectively. Worker flows are movements of workers through firms and economic sectors and are measured by aggregating hires and separations at individual firms. Job flows are movements of jobs and are measured by aggregating the absolute value of net changes in firms' payrolls. Lastly, churning flows are the excess of worker flows over job flows. We use data from the formal labour market in Colombia, a middle-income developing economy, for the period between October 2008 and December 2014. We aggregate these measures for the 23 main metropolitan areas in Colombia. Our definition of a firm is broad: in this paper, a firm is a single or multi-establishment business in a city, with at least two employees in total. These must be formal establishments, defined as those that account for payroll taxes and employee social security contributions.

One of the strengths of this paper is that we use a unique data set generated from the administrative records of the Colombian Social Security Bureau. We use these records to assemble longitudinal employer-employee data for all formal firms in the country, enabling us to compute fluidity measures for all economic sectors. Most papers in the literature on job and worker flows use plant-level data, which at best are samples for specific economic sectors, usually manufacturing. Some studies use information for all formal firms in all sectors, but restricted to a specific geographical area in a country, such as a particular state in the United States (Burgess, Lane and Stevens, 2000). Most of what we can learn from the literature on worker and job flows concerns the manufacturing sector and uses rotating panels (Davis, Haltiwanger and Schuh, 1996). ${ }^{2}$

The effect of fluidity on labour market performance may be positive if an increase in fluidity is associated with a reduction in the cost of transitioning in the market, which is likely to affect the aggregate productivity of the economy positively (Molloy and others, 2016). In addition, there are empirical and theoretical grounds for considering the effect of fluidity on labour market performance to be favourable. First, empirical studies find that the reallocation of workers across different firms and sectors is procyclical, especially when there is an excess of worker reallocation over job reallocation (churning) (Akerlof and others, 1988; Davis, Haltiwanger and Schuh, 1996). Second, search models of equilibrium unemployment, allowing for job-to-job transitions, predict that factors which reduce search costs and therefore increase worker reallocation will lower the equilibrium rate of unemployment.

Our findings include evidence that the formal labour market in Colombia became more fluid after the last quarter of 2010 and that this coincided with a substantial decrease in the unemployment rate. ${ }^{3}$

\footnotetext{
2 Examples of these information sources are the Longitudinal Research Database (Davis, Haltiwanger and Schuh, 1997) and the Job Openings and Labor Turnover Survey (Davis and Haltiwanger, 2014). In the case of rotating panels, corrections have to be made to prevent overestimation of the fluidity measures; our fluidity measure is valid without need of correction because we observe the whole universe of formal firms.

3 This evidence has been corroborated by recent studies on Colombia, such as Morales and Lobo (2017).
} 
In addition, we estimate econometric models to capture the causal relationship between the measures of fluidity and some labour market outcomes. The results we analyse in this paper are outcomes in the salaried-formal labour market, mainly because the fluidity measures we are able to generate from our data are exclusively for salaried-formal workers and jobs. Specifically, the dependent variables of the models in this paper are formal employment rates (the formal wage-earning employed population as a proportion of labour market participants) and formal occupation rates (the formal wage-earning employed population as a proportion of the working-age population).

We find a benign and sizeable effect of the WR, JR and CR on several of our labour market outcomes. In general, we present evidence that increases in labour market fluidity yield growth in formal employment and formal occupation levels for the working-age population. Davis and Haltiwanger (2014) reach a similar conclusion for the United States labour market; nevertheless, to the best of our knowledge, no other study in the literature offers an empirical assessment of the hypothesis that fluidity benefits formal labour markets in developing economies. In Colombia, like many other developing countries, informality is a major problem, but the formal labour market is still sizeable and significant. In the 23 largest cities of Colombia, formal employees were nearly $51 \%$ of all employees in 2016 , while in the Latin American region as a whole, the formal labour market represented $54 \%$ of the total in 2015 . For developing countries, therefore, it is also crucial to reach a deeper understanding of the causal effects of fluidity on the performance of the formal labour market, especially since there is an ongoing debate in many of them about the undesirable consequences of economic policies that make labour markets more rigid and sclerotic. ${ }^{4}$

The next section of this paper begins by describing the fluidity measures employed, something that is crucial for understanding the rest of it. The third section carries out an empirical and theoretical review of the literature on the relationship between worker and job dynamics and labour market performance. The fourth section describes the data sources and the fifth comments on the recent dynamics of fluidity measures in Colombia. The sixth section presents the empirical model and the seventh the results of the estimations. The last section concludes and sets out some general policy implications.

\section{Fluidity measures}

For the purpose of calculating worker and job flows, a job is defined as a position filled by a worker (Davis, Haltiwanger and Schuh 1996). All our measures are therefore based on observations of the size of a firm and the flow of workers entering and exiting it. We measure these flows on a monthly basis for all firms defined as formal in Colombia from October 2008 to December $2014 .{ }^{5} \mathrm{~A}$ firm $j_{t}$ is a set of business establishments in the same city with at least two employees, and the firm belongs to the formal sector if it accounts for payroll taxes. An individual $i_{j t}$ is an employee on the payroll of firm $j$ in period $t$.

Administrative records are used to generate a linked employer-employee longitudinal data set by observing the payroll of a given firm on a monthly basis. This data structure is used to compute hires $\left(h_{j t}=\left\{i: i_{t} \in j_{t}\right.\right.$ and $\left.\left.i_{t} \notin j_{t-1}\right\}\right)$ as the set of employees who are observed in a given period and were not observed before. Similarly, separations $\left(s_{j t}=\left\{i: i_{t} \notin j_{t}\right.\right.$ and $\left.\left.i_{t} \in j_{t-1}\right\}\right)$ are computed from employees who were observed in the previous period and are not observed in the current one. Lastly, stayers $\left(k_{j t}=\left\{i: i_{t} \in j_{t}\right.\right.$ and $\left.\left.i_{t} \in j_{t-1}\right\}\right)$ are the set of employees observed in both periods.

4 Sclerotic labour markets are characterized in Blanchard and Portugal (2001) as rigid and static markets. They present low rates of entry into and exit from unemployment and high mean unemployment duration.

5 The electronic Unified Social Security Contributions Form (PILA) was rolled out in 2008, but use of data from its first six months of operation is unadvisable because some firms started reporting somewhere between January and June 2008. As a precaution, information from that system is only used from a trimester later, by which time all firms then operating were reporting to PILA. Our estimates are checked for robustness by changing the first month from which the fluidity variables are measured; the results do not change significantly. This robustness check is discussed in footnote 23. 
The payroll of the firm in a given period is denoted as $e_{j t}=k_{j t}+h_{j t}$. The number of jobs created and destroyed is approximated from the changes in the payroll from one period to the next. Therefore, job creation $c_{j t}$ and job destruction $d_{j t}$ at firm $j$ in period $t$ are denoted as $c_{j t}=1_{\left\{\Delta e_{j t}>0\right\}} \Delta e_{j t}$ and $d_{j t}=-1_{\left\{\Delta e_{j t}<0\right\}} \Delta e_{j t,}$,respectively. Summations of all these sets are used to generate aggregate measures of fluidity in a local labour market $A$ (a metropolitan area). Therefore, the aggregate flows of hires $\left(H_{A, t}\right)$, separations $\left(S_{A, t}\right)$, job creation $\left(C_{A, t}\right)$ and job destruction $\left(D_{A, t}\right)$ in local labour market $A$ can be represented as $H_{A, t}=\sum_{j \in A} h_{j t}, S_{A, t}=\sum_{j \in A} s_{j t}, C_{A, t}=\sum_{j \in A} c_{j t}$ and $D_{A, t}=\sum_{j \in A} d_{j t}$, respectively. ${ }^{6}$

We follow the previous literature on the subject (Davis, Haltiwanger and Schuh, 1996; Davis and Haltiwanger, 1992), defining firm size as the moving average of order two of the firm's employment, as represented by the following equation: $x_{j t}=\left(e_{j t}+e_{j t-1}\right) / 2$. Total firm size in a metropolitan area is defined as $X_{A, t}=\sum_{j \in A} x_{j t}$. We express worker flows (hires and separations) and job flows (job creation and destruction) as the total labour market employment rate $X_{A, t}$. The fluidity measures used in this paper are thus defined as follows:

Worker reallocation rate ${ }^{7}(\mathrm{WR})\left[W R_{A, t}=\left(H_{A, t}+S_{A, t}\right) / X_{A, t}\right]$ : This is the sum of monthly rates of hires and separations. Worker reallocation reflects the number of people changing either their employer or their employment status (employed/unemployed) from one period to the next (Davis, Haltiwanger and Schuh, 1996). It measures the number of workers entering or exiting firms.

Job reallocation rate $(\mathrm{JR})\left[J R_{A, t}=\left(C_{A, t}+D_{A, t}\right) / X_{A, t}\right]$ : This is the sum of the monthly job creation and destruction rates. Job reallocation is the amount of employment gained and lost from one period to the next (Davis, Haltiwanger and Schuh, 1996). It measures opportunities for moving from shrinking to expanding firms.

Churn rate (CR) $\left[C R_{A, t}=\left(H_{A, t}-C_{A, t}+S_{A, t}-D_{A, t}\right) / X_{A, t}\right]$ : This is the difference between the WR and the JR, usually characterized as an excess of worker flows over and above the amount required to accommodate job flows (Davis and Haltiwanger, 2014). The churn rate captures the number of hires that are not jobs created and the number of separations that are not jobs destroyed. Churning jobs are those that arise from replacing workers who were separated from their jobs either because they resigned or because they were dismissed as their firms sought to better match their staffing to their needs.

\section{The relationship between labour market fluidity and outcomes}

We present evidence in a later section of this paper that labour market fluidity has increased in Colombia in recent years. The literature has identified several good and several undesirable aspects of more fluid labour markets. A positive relationship between some fluidity measures and the economic cycle has been documented in several papers, but only for developed economies. There are also some standard theoretical frameworks that predict a negative relationship between certain fluidity measures and the equilibrium unemployment rate. In this section, we delve into the empirical and theoretical relationship between fluidity and economic performance, placing emphasis on equilibrium unemployment.

The literature has identified undesirable aspects of labour market fluidity associated with the reallocation of jobs. Some of these will now be discussed. Increases in the JR will increase unemployment if they are the result of job destruction exceeding job creation. A reduction in the JR may also be

\footnotetext{
${ }^{6} H_{A, t}\left(S_{A, t}\right)$ represents all hires (separations) in metropolitan area $A$ in period $t . C_{A, t}\left(D_{A, t}\right)$ represents all employments gains (losses) at new (exiting) and expanding (shrinking) establishments. $X_{A, t}$ measures the volume of employment in local market $A$.

7 This is sometimes referred to as worker turnover in the literature.
} 
associated with greater job security and a lower incidence of unemployment, which are desirable labour market characteristics for many reasons. For example, the loss of a job can mean lower earnings for many years after the episode of unemployment (Davis and Haltiwanger, 2014). ${ }^{8}$ Lastly, there is an empirical regularity in the literature on labour market flows: the inverse relationship between firm size and the pace of job reallocation (Davis and Haltiwanger, 1999). On this evidence, a reduction in the JR can be associated with higher productivity. The argument for this association is that the decline in the JR may be driven by growth in firm size, as bigger firms evince lower reallocation measures while also having higher productivity.

Benign aspects of labour market fluidity have also been identified in the literature. An increase in the JR may be due to more new jobs being created than existing ones destroyed. In addition, a more fluid labour market will decrease the average duration of unemployment because it implies an increase in the frequency of job offers. There is the expectation of a direct relationship between fluidity and job mobility, with more fluid markets being associated with greater potential for employees to change careers or move into better positions, which is a desirable characteristic in labour markets. Regarding the employer-employee matching process, the quality of this may be better in markets that are more fluid. Akerlof and others (1988) argue that job-to-job mobility is highly procyclical and improves matching between workers and jobs, creating an additional welfare benefit from reductions in unemployment.

An additional argument for the benefits of fluid markets is that fluidity may be the result of a less rigid labour market. Several papers find that employment protection laws reduce labour market fluidity (Blanchard and Portugal, 2001; Gómez-Salvador, Messina and Vallanti, 2004; Boeri and Jimeno, 2005; Decker and others, 2014). There is extensive evidence that a less rigid labour market produces better aggregate results, such as lower unemployment rates and higher productivity in the economy. For the specific case of the North American economy, Autor, Donohue III and Schawb (2006) and Autor, Kerr and Kugler (2007) present evidence for the adverse effects of labour protection laws on employment and total factor productivity.

There is a substantial body of literature on labour market flows, focusing on data from the United States manufacturing sector. This empirical literature has questioned the ability of standard views of the real business cycle to explain movements of workers and jobs in the economy. According to the prevailing macroeconomic framework of real business cycle models, worker and job flows should be neutral to the economic cycle. The data do not well support these predictions; instead, what is observed from the United States manufacturing sector can be roughly summarized as follows. The JR is negatively correlated with net changes in employment; in other words, the economy restructures the organization of jobs in recessions (Davis, Haltiwanger and Schuh, 1996). Nevertheless, according to Akerlof and others (1988), the WR is mildly procyclical. Since the portion of the WR that corresponds to the JR is countercyclical, then, it must be the case that the excess of worker reallocation over job reallocation (the churn rate) is highly procyclical. It should be pointed out that most of the literature cited computes simple unconditional correlations between a measure of the economic cycle and the labour reallocation rate.

Some quite recently developed theoretical frameworks are helpful for understanding the influence of worker and job flows on labour market performance. The best model for this purpose is Pissarides' equilibrium unemployment theory (Pissarides, 2000). In a fairly general version of the influential Pissarides search model, a theoretical prediction is that increases in worker flows will reduce equilibrium unemployment. A search model with endogenous job destruction and on-the-job search unambiguously predicts that an increase in worker flows (job-to-job transitions) originating from reductions in on-the-job

\footnotetext{
8 Several studies have evaluated the impact of an episode of unemployment on a variety of outcomes, from health to psychological well-being, finding substantial negative effects. For a review of this literature, the reader may refer to Davis and Von Wachter (2011).
} 
search costs will reduce job destruction, increase job creation and lower equilibrium unemployment. ${ }^{9}$ This effect will be enhanced if the increase in worker flows somehow induces a quality enhancement in job-worker matching that in turn increases labour productivity. There is not much literature providing evidence for this conjecture; nevertheless, Akerlof and others (1988) show that fluid labour markets yield better job-worker matching.

In this paper, we test what Davis and Haltiwanger (2014) call the "fluid market hypothesis". This hypothesis establishes that fluid labour markets promote higher levels of employment. The first study to assess a causal relationship between fluidity and employment was Shimer (2001). This paper finds the proportion of young people in the working-age population to have a positive effect on employment. In the model proposed there, this happens mainly because the larger the proportion of young people in the working-age population, the cheaper it is for firms to recruit new workers. Under these circumstances, firms will find it more profitable to create employment for younger jobseekers, thus boosting job creation and reducing unemployment (Shimer, 2001).

Davis and Haltiwanger (2014) propose an additional mechanism through which fluidity may boost employment: fluid labour markets imply workers receiving more frequent job offers, which in turn has the effect of shortening jobless spells. From the worker's point of view, shorter jobless spells avoid loss of human capital, increasing the incentives to work in the future. In addition, firms may discriminate against persons who have been out of work for longer, and shorter average unemployment spells in the economy should reduce the adverse effects of this. Research on worker/job flows in labour markets is highly focused on developed economies. ${ }^{10}$ Furthermore, papers on labour market fluidity and its effects on employment have appeared only fairly recently and are not numerous. Our paper contributes to the literature in at least two ways. First, it is one of the few papers to have found effects of fluidity on employment and labour demand, and to the best of our knowledge there is no other study of the effect of fluidity on labour market outcomes for a developing economy. Second, our data are unique in covering all formal firms in the Colombian economy, which means that our conclusions are not restricted to the manufacturing sector, as they are in most studies on worker/job flows and fluidity.

Studying the consequences of fluidity for formal employment and formal labour demand in developing economies is crucial in countries like Colombia where nearly half of all employees have formal jobs; identifying the consequences of greater labour market fluidity for formal job creation is a key factor in understanding these markets. For various reasons, especially the lack of data, there have been very few attempts to understand flows of workers and jobs in developing countries and their consequences, and this is a gap in the literature that this paper seeks to fill.

\section{The data}

The data used in this paper come from two different sources. The fluidity measures are generated from the administrative records of the Unified Social Security Contributions Form (PILA). ${ }^{11}$ PILA is a unique source of longitudinal information, covering wages, contributions to retirement funds and health

9 Technically, in a traditional diagram showing the Beveridge curve and the job creation line in a vacancies-unemployment space, an increase in the population searching on the job shifts and steepens the slope of the job creation line, reducing all possible unemployment equilibrium rates regardless of what happens with the Beveridge curve. Nevertheless, under the most standard assumptions, the Beveridge curve shifts to the left, increasing the reduction in the equilibrium unemployment rate.

10 There has recently been increasing interest in this topic as it affects the Latin American region, especially where job flows are concerned. The most comprehensive description of job creation in the Latin American region can be found in Pagés, Pierre and Scarpetta (2009). Previous work on labour market flows in Colombia has focused on measures of job creation and job destruction for the manufacturing sector (Melo and Ballesteros, 2013 and 2014).

${ }^{11}$ The Ministry of Social Security in Colombia designed and implemented an integrated system for collecting all social security-related payments that employers are required to make. When making these payments, employers must fill in a form with information on each employee on their payroll. 
insurance, some basic demographic characteristics and some basic features of the firms concerned. We used this information source to construct a linked employer-employee longitudinal data set with firms observed at least once during the period from October 2008 to December 2014. For the same period, we generated labour market outcomes and additional control variables by using Colombia's official Large Integrated Household Survey (GEIH). ${ }^{12}$ To summarize, our data include fluidity measures, labour market outcomes and controls for the 23 main metropolitan areas in Colombia on a monthly basis from October 2008 to December 2014.

The focus of this paper is on wage employees working in formal firms, defined as those that account for payroll taxes and contributions to the social security system. Figure 1 represents formal wage employment of different kinds. The solid line is employment at formal firms with more than five employees as reported via PILA. The solid dark and dashed lines are formal employment and total wage employees, with figures provided by the GEIH. ${ }^{13}$ All measures of employment show it to have increased substantially, especially since 2009. This increase in the number of employees has gone together with a period of remarkable economic growth in Colombia.

Figure 1

Total formal employment, quarterly moving averages, seasonally adjusted monthly series, October 2008 to December 2014

(Thousands)

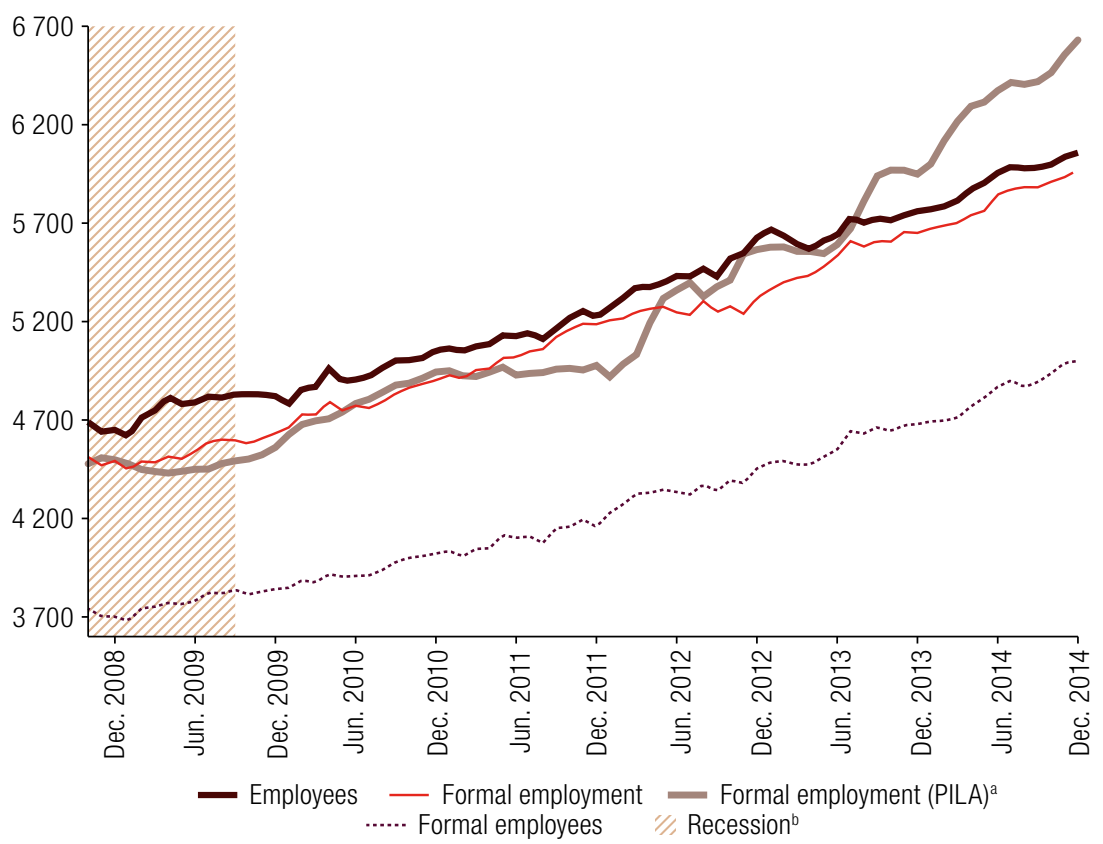

Source: Prepared by the authors.

a Firms with more than five employees reporting via the Unified Social Security Contributions Form (PILA), without data imputation.

b A recession is defined as a period with two consecutive contractions in GDP.

\footnotetext{
12 The GEIH is applied on a monthly basis by Colombia's National Administrative Department of Statistics (DANE) and is representative of the country's 23 largest metropolitan areas.

${ }^{13}$ The definition of a formal worker used by the National Administrative Department of Statistics (DANE) is "a wage employee in a firm with more than five employees or a professional self-employed worker".
} 


\section{The recent dynamics of fluidity measures in Colombia}

Figure 2 shows the flows that are the basis of traditional fluidity measures in the literature: hires, separations, job creation and job destruction during the period between October 2008 and December 2014. Figure 2.A presents flows in moving averages of order three. The first thing to note is that during the period studied in this paper all flows show remarkable increases, especially after the last period of economic recession (June 2008 to December 2009). Flows of hires (separations) rose from 410,400 $(389,100)$ workers in the period from January 2009 to June 2010 to nearly 632,800 $(594,200)$ workers in the period from January 2013 to December 2014. Similarly, the number of jobs created (destroyed) increased from 193,100 $(201,200)$ in the period from January 2009 to June 2010 to 307,000 $(333,700)$ in the period from January 2013 to December 2014. This period of expanding flows coincided with a good performance in the Colombian economy: the annual growth rate was at least $4 \%$ in every year after 2009. Before this, Colombia's economic growth was slowing, and real GDP grew by just 1.65\% in 2009, a low figure in comparison with subsequent rates.

The relationship between worker and job flows can be characterized from the information in figure 2. From October 2008 to December 2014, the average seasonally adjusted flow of workers hired by all formal firms in Colombia was 507,000, while an average of 265,000 new jobs were created in the same period. Roughly $52 \%$ of all hires were replacements for existing workers and not new jobs. Similarly, the average seasonally adjusted flow of workers separated from formal firms in Colombia was 477,000 , while 234,000 jobs were destroyed. Roughly $49 \%$ of all separations were because workers were replaced rather than jobs destroyed. In addition, it can be noted that the change in employment is positive (negative) when creation is greater (less) than destruction. It is also true that the net change in employment must be equal to hires minus separations, whence the change in employment is likewise positive (negative) when there are more (less) hires than separations.

Figure 2

Hires, separations and job creation and destruction in 23 metropolitan areas, quarterly moving averages, October 2008 to December 2014

(Thousands)

A. Monthly gross formal employment, hires and separations

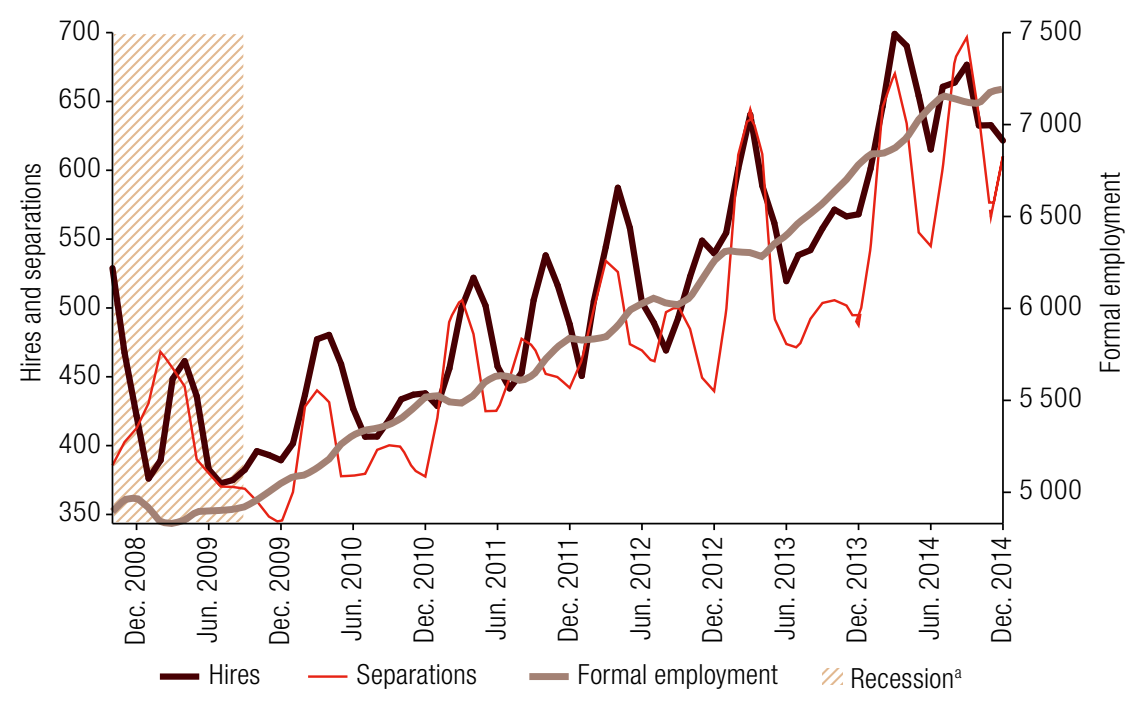


B. Monthly gross formal employment, job creation and job destruction

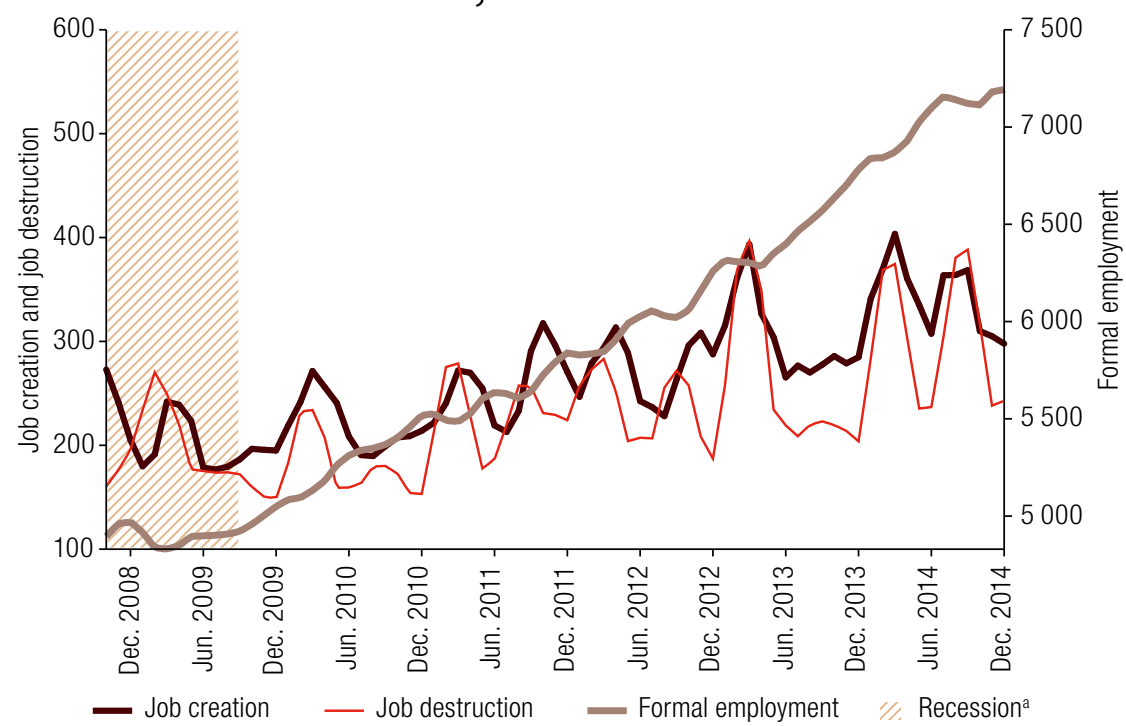

Source: Prepared by the authors.

a A recession is defined as a period with two consecutive contractions in GDP.

Figure 3 illustrates the relationship between net changes in employment and hiring and separation flows, showing how job creation and destruction rates are related to separation and hiring rates. It presents a scatter plot of net employment growth rates ${ }^{14}$ and hiring and separation rates (median) observed from establishment-level data, describing the close relationship between worker flows and employment growth and showing that growth is positive when the hiring rate is above the separation rate. On the one hand, separation rates for shrinking firms are extremely high, while hiring rates are low and flat; on the other hand, hiring rates for expanding firms are extremely high and separation rates are low and flat.

The behaviour of firms is symmetrical in expansions and contractions. The relationship between net growth and hiring or separation rates has what the literature usually refers to as hockey stick shapes. In both cases, the pairs of hiring (separation) rates and net growth rates are above a 45-degree line. This is to be expected, since a small but non-zero level of hiring is observed in contractions, while a modest but non-zero level of separations is observed in expansions. ${ }^{15}$ In expansions, for example, the hiring rate has to be greater than the growth rate to compensate for separations. Interestingly, in significant expansions and contractions, the lines corresponding to hires and separations in figure 3 are even farther away from the 45-degree line. Thus, for example, there are rapid expansions with a noticeably higher rate of separations. This makes sense because rapid expansion requires a higher level of separations to maintain the quality of the employer-employee match.

\footnotetext{
${ }^{14}$ Net employment growth rates are defined as the ratio between changes in employment and firm size defined as $x_{j t}=\left(e_{j t}+e_{j t_{-}-1}\right) / 2$.

15 The relationship between hires, separations and employment growth rates follows similar patterns across different economies. A version of figure 3 presented by Davis, Faberman and Haltiwanger (2012) for the United States economy is similar to what is presented in this paper. This is because of the close relationship between worker flows and employment growth; as any economic model of labour demand would predict, firms should expand as a result of increases in hiring and contract as a result of increases in separations.
} 
Figure 3

Cross-sectional relationship between worker flows and net employment growth at the establishment level, 23 metropolitan areas, October 2008 to December 2014 (Percentages)

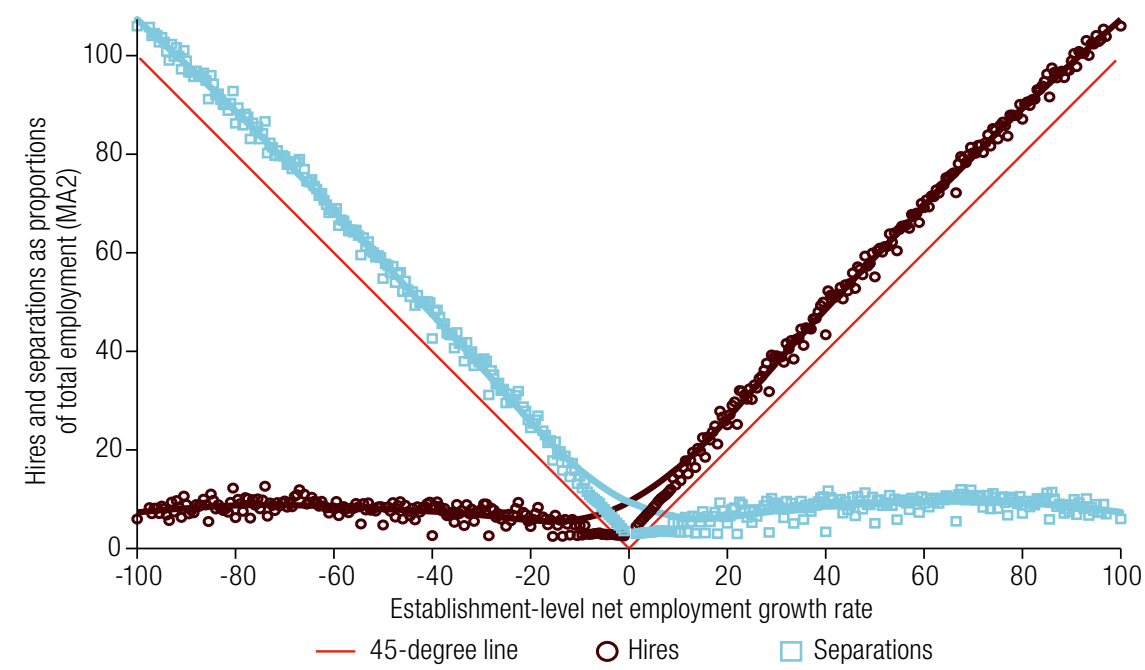

Source: Prepared by the authors, on the basis of S. J. Davis, J. Faberman and J. C. Haltiwanger, "Labor market flows in the cross section and over time", Journal of Monetary Economics, vol. 59, No. 1, Amsterdam, Elsevier, 2012.

Note: Estimates are the employment-weighted average of the establishment-level growth rates within intervals ( 0.5 percentage points). MA2 is a moving average sthocastic process with two temporary lags.

Figure 4.A shows flows of workers and jobs presented as percentages of employment levels in the metropolitan areas. Figure 4.B shows worker reallocation rates (WR) and job reallocation rates (JR) and the combination of the two, the churn rate (CR). Figure 4.A shows that rates of hires and separations were between $6.6 \%$ and $12.0 \%$ during the period studied. The average hiring rate was $8.9 \%$, while the average separation rate was $8.4 \%$. At times when the hiring rate is above the separation rate, a large reduction in the level of unemployment is observed (figure 4.B).

\section{Figure 4}

Fluidity measures, 23 metropolitan areas, quarterly moving averages, October 2008 to December 2014 (Percentages of employment)

A. Monthly rates of hires, separations and job creation and destruction

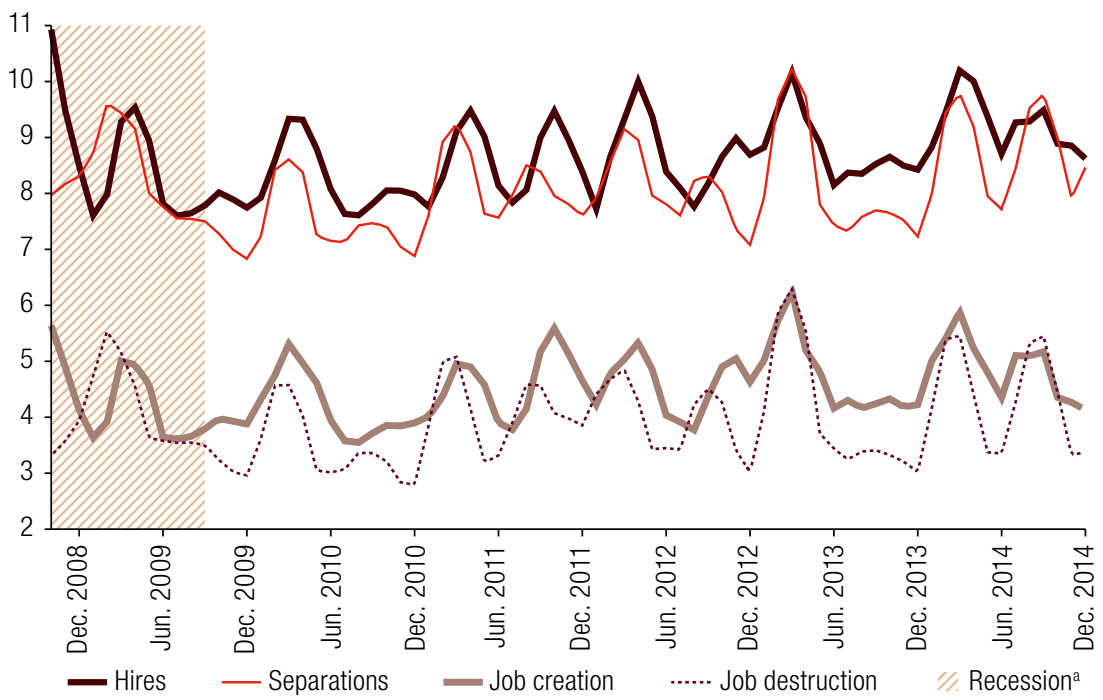


B. Monthly rates of job reallocation, worker reallocation and churning

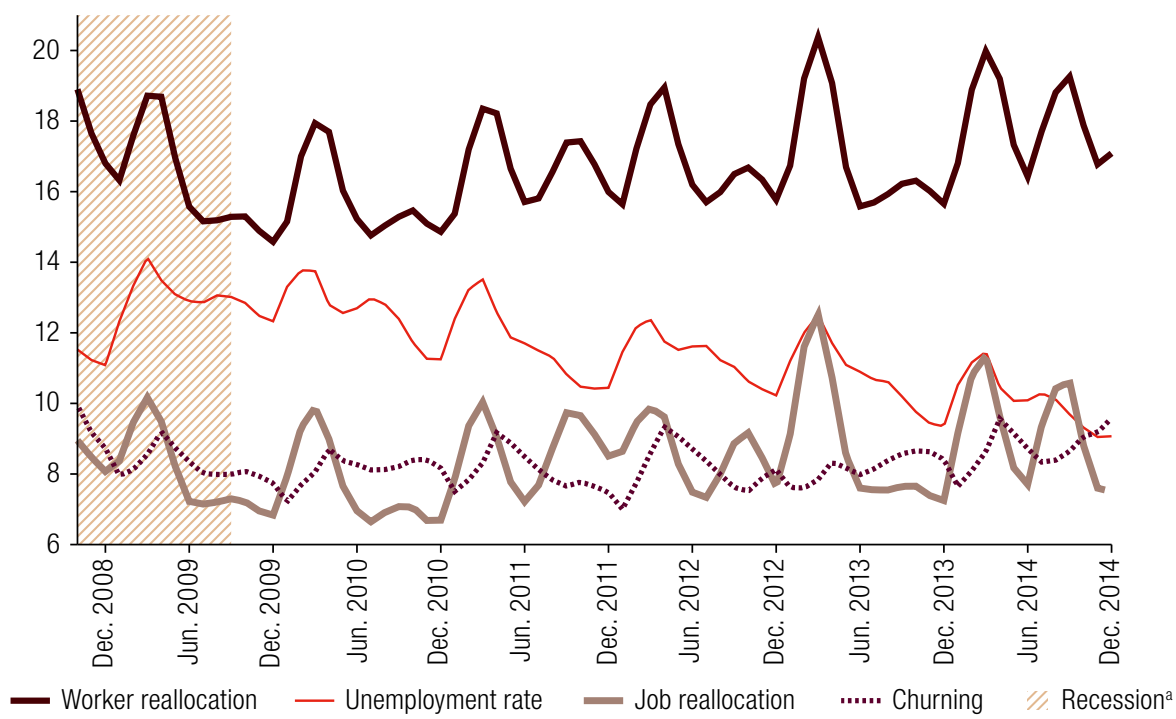

Source: Prepared by the authors.

a $A$ recession is defined as a period with two consecutive contractions in GDP.

As mentioned earlier, job creation and destruction rates are just proportions of hiring and separation rates, respectively. On average, the job creation rate is $60 \%$ of the hiring rate and the destruction rate is $57 \%$ of the separation rate. Thus, destruction represents a greater percentage of total separations than creation of total hires, which is consistent with the reduction in unemployment observed during the period. Figure 4.B shows that both the WR and the JR present a noticeable increase in magnitude and volatility after the last trimester of 2010 . The combination of the two yields the churn rate (CR), which also increased after 2011.

Figure 4.B compares the evolution of unemployment and our three measures of labour market fluidity, the churn rate (CR), the worker reallocation rate (WR) and the job reallocation rate (JR). In all three cases, there seems to be a negative relationship between unemployment and all three measures after 2009. When unemployment shows a decreasing trend, the fluidity measures seem to increase.

In this study, unlike most of the literature, labour flows are measured for all formal sectors of the Colombian economy, not only manufacturing. It is not the intention of this paper to characterize the heterogeneity of labour market fluidity across different economic sectors; nevertheless, mention may be made of some of the evidence collected in Flórez and others (2018), which carries out an indepth analysis of the heterogeneity of labour flows in the Colombian formal market. One of the most salient conclusions of that study ${ }^{16}$ is that manufacturing, the most studied sector in the international literature, is one of the least dynamic sectors in the labour market: the WR, JR and CR were lower for the manufacturing sector than for any other during the period 2009-2016. In general, all other economic sectors have fairly similar reallocation rates, but there is one that stands out for its high rates, namely construction. The causes and consequences of this heterogeneity in labour dynamics are still an unexplored issue in the literature.

\footnotetext{
${ }^{16}$ The monthly WR rates estimated for the Colombian formal labour market in Flórez and others (2018) show WR rates of 11.84\% for the manufacturing sector and 18\% for the labour market as a whole during the period 2009-2016. The construction sector had a WR rate of $36 \%$ for the same period.
} 


\section{The empirical model}

The purpose of this paper is to identify the role that labour market fluidity plays in employment and occupation rates. The definition of "labour market" is a metropolitan area. There are 23 main metropolitan areas in Colombia. We compute standard fluidity measures and control variables for each metropolitan area in each period (month) from October 2008 to December 2014. The equation that we estimate can be represented as:

$$
y_{i t}=x_{i t}{ }^{\prime} \beta+\delta_{i}+\tau_{i, t}+\alpha f_{i t}+\varepsilon_{i t}
$$

where $y_{i t}$ is the labour market outcome (employment and occupation rates defined for formal wage workers) in metropolitan area $i$ at period $t, \delta_{i}$ is the fixed effect by metropolitan area, the vector $x_{i t}$ contains a series of control variables that vary by metropolitan area, and $\tau_{i, t}$ denotes a series of fixed effects over time. The coefficient of interest is $\alpha$, which captures how the labour market outcome $y_{i t}$ changes when the fluidity measure $f_{i t}$ increases by 1 percentage point. The control variables we include in vector $x_{i t}$ are the following: the hourly wage deflated by the implicit GDP deflator; the proportion of the workingage population with tertiary education; the proportion of private sector firms; employees' average age; the proportion of males in wage employment; department-level labour demand; ${ }^{17}$ GDP per person employed; employers' costs; the Hodrick-Prescott filter for quarterly GDP; and state annual GDP growth.

There are a number of reasons why $\alpha$ can be affected by endogeneity bias. There may be timevarying unobserved factors in the metropolitan area that determine the labour market outcome $y_{i t}$ whilst being correlated with the fluidity measure $f_{i t}$. In addition, given that we construct fluidity measures from administrative records, these measures may be subject to measurement errors; for example, firms may misreport their payroll information for some periods. These imperfections in the linked employeremployee longitudinal data set lead to the fluidity measures being miss-estimated, and it may be that the measurement error in fluidity measures is not random. For all these reasons, we estimate instrumental variable models.

\section{Instrumental variables}

Drawing on the previous literature, we construct plausible valid instruments for each of our endogenous variables. We use two types of instruments. First, we use local labour market characteristics that, depending on the control variables included in the regressions, are assumed to be exogenous. Second, following Davis and Haltiwanger (2014), we construct instruments based on national-level measures of fluidity intensity by economic sectors; these instruments map changes in national labour market fluidity on to metropolitan area fluidity intensity.

Instruments based on the characteristics of local markets: We use a series of instruments based on the idea that low-skilled young workers have the greatest labour market mobility (Shimer, 2001; Davis and Haltiwanger, 2014). First, we take the population aged between 18 and 24 with less than secondary education and at most complete secondary education, both as a share of the working-age population. Second, we take the minimum wage, on the basis that it necessarily applies to low-skilled young workers. A condition for using these instruments is that the median hourly wage in each local labour market is controlled for. The minimum wage is an exogenous factor frequently imposed on the market by the government. ${ }^{18}$ Furthermore, workers and firms, acting individually, have virtually no

\footnotetext{
17 Section VI.1 explains in detail how this control was constructed.

18 In five of the seven years from 2008 to 2014 , the government imposed the minimum wage because negotiation between unions and firms did not accomplish any agreement.
} 
opportunity to influence it. Therefore, by controlling for the average wage per metropolitan area, we can assume that the minimum wage is uncorrelated with the error in equation (1).

Instruments based on the reallocation intensity of economic sectors: In this case, we follow the literature on local labour demand measures. Bartik (1991) designs a measure for changes in local labour demand unrelated to local labour supply. The idea is to map "national" employment changes on to local employment changes (by "national" we mean total minus local employment). This is done by averaging national employment changes across industries using local industry employment shares as weights. In this paper, we use Bartik's original index of changes in local labour demand as a control variable, constructed as follows:

$$
\begin{gathered}
B_{a t}=\sum_{k=1}^{K} \gamma_{k a t-1} \cdot \Delta_{k t}^{-} \\
\text {where } \Delta_{k t}^{-}=\frac{\Delta E_{k t}^{-}}{1 / 2\left(E_{k t}^{-}+E_{k t-1}^{-}\right)}
\end{gathered}
$$

with $\gamma_{k a t-1}$ being the employment share of local market $a$ in economic sector $k$ and $\Delta_{k t}^{-}$the change in employment in economic sector $k$ at time $t, E_{k t}^{-}$, as a percentage of our measure of firm size (excluding local labour market $a$ ). This special growth rate is often used in the literature on worker/job flows and is known as Davis, Haltiwanger and Schuh (DHS) net employment growth (Davis, Haltiwanger and Schuh, 1996). The variable $B_{a t}$ predicts what the net employment change in local labour market $a$ would have been given the net employment growth in other labour markets and its own industrial composition.

Several papers have constructed instruments following Bartik's original idea. Good examples of these are Blanchard and Katz (1992), Bound and Holzer (2000) and Autor and Duggan (2003). For the specific study of labour market fluidity, Haltiwanger and Davis (2014) propose a series of instruments that result from the interaction between Bartik-like local labour demand indices and job reallocation rates. In this paper, we draw on the whole of this earlier literature to design our reallocation intensity instrument as follows:

$$
B I_{a t}=\sum_{k=1}^{K} \gamma_{k a t-1} \cdot f_{k t}^{-}
$$

where $f_{k t}^{-}$is a fluidity measure (WR, JR, CR) for sector $k$ computed nationally, but excluding local market $a$. In addition, $\gamma_{k a t-1}$ is the employment share of local market $a$ in economic sector $k$ in the previous period. This instrument captures the interaction of the fluidity measures for different industries in other labour markets given the previous industrial composition in the local labour market. The instrument $B I_{a t}$ uses national fluidity measures (excluding the local level) for different economic sectors to predict local fluidity measures. In the construction of these instruments, the "national" fluidity measures are weighted by the lagged share of a sector's employment in the local industrial composition.

Comments on the validity of the instruments: Regarding the first set of instruments, we assume they are exogenous given the set of controls that we use in the structural equation. Let us consider the real minimum wage, this could be correlated with the business cycle and other relevant factors affecting the performance of the labour market even though it is usually imposed by the government. We therefore include GDP per person employed, a Hodrick-Prescott filter of quarterly GDP and annual departmental GDP growth as control variables in our structural equation. In addition, we control for the average wage in the MA. Given that we are controlling for the economic cycle and the effect of average wages on labour market outcomes, we assume that minimum wages are uncorrelated with the error term in equation (1). In the case of the shares of the population aged between 18 and 24 with different levels of education, these variables are usually assumed to be exogenous in the literature because they 
are heavily influenced by demographic trends; they are therefore unlikely to correlated with economic cycles or time-varying unobserved heterogeneity. ${ }^{19}$

With regard to Bartik-like instruments, we include $B_{a t}$ as a control variable in our structural equation; we assume that the $B I_{a t}$ instruments are uncorrelated with the error term in equation (1) on condition that this variable is included in the regression. This may be the case for the following reasons. First, these instruments isolate changes in reallocation intensities that derive from changes in industry-level reallocation intensity. They are computed using other metropolitan area reallocation measures and the lagged employment composition of a particular metropolitan area (Davis and Haltiwanger, 2014). Second, we control for several measures of the economic cycle and predicted changes in labour demand using other metropolitan area changes in labour demand. Since we control for $B_{a t}$, Bartik-like instruments are not correlated with time-varying shocks that affect labour demand at the industry level; therefore, the only way reallocation at the industry level could plausibly affect labour market outcomes is through its effect on local reallocation.

We use overidentified models in all our instrumental variable regressions, employing several of the instruments proposed in the previous paragraphs. We use the statistics of the joint significance test (F-test) in the first stage to test the strength of our instruments. We use the standard test for overidentifying restrictions to test the validity or exogeneity of additional exclusion restrictions. ${ }^{20} \mathrm{~F}$-statistics from the first stage are greater than 13 in all cases, and in no case do we reject the hypothesis that the instrument is valid in terms of identification restrictions.

\section{Results}

In this section, we show the estimation results of equation (1). Given that we can only generate our fluidity measures for formal wage employees, ${ }^{21}$ the outcomes that we study relate to formal wage-paying labour markets. The inability to observe the informal market is a limitation of this study. ${ }^{22}$ Nevertheless, it is a step forward in the literature because, to the best of our knowledge, the relationship between fluidity and labour market performance has not been studied before in the context of the Latin American region or even developing economies in general. We focus on two labour market outcomes in particular: on the one hand, the share of salaried-formal workers as a proportion of the total labour force; on the other hand, the proportion of salaried-formal workers as a proportion of the total working-age population. The first variable is a component of the employment rate and will be referred to as the formal employment rate. The second the other variable is the formal-salaried occupation rate (formal wage workers as a proportion of the working-age population).

Table 1 shows summary statistics for controls, dependent variables and fluidity measures. The period studied was characterized by a reduction in unemployment and substantial economic growth, so it is not surprising that the average hiring rate $(9.22 \%)$ was greater than the average separation rate $(8.47 \%)$, or that the average job creation rate $(5.57 \%)$ was greater than the average job destruction rate (4.81\%). We can characterize the average ratio between worker and job flows from these numbers. As can be seen, around $60 \%$ of all hiring was accounted for by new jobs and around $57 \%$ of all separations by jobs destroyed. The data from which we compute our fluidity measures contain information on more

\footnotetext{
${ }^{19}$ In the specific case dealt with here, these demographic instruments are unlikely to be correlated with the measurement error of fluidity measures because the two variables come from different sources.

20 The statistic for the overidentifying restriction test is computed as $N \times R_{u}{ }^{2}$, where $N$ and $R_{u}$ come from an auxiliary regression of $\hat{\varepsilon}_{i t}$ on [XZ]. In this auxiliary regression, $X$ stands for the matrix of exogenous covariates and $Z$ stands for the matrix of instruments; $N \times R_{u}{ }^{2}$ is distributed $\chi^{2}$ with degrees of freedom equal to the number of overidentifying restrictions. The null hypothesis of this test is the exogeneity of the instruments, mathematically, $H_{0}: E\left(Z^{\prime} u\right)=0$.

${ }^{21}$ Formal in the sense of working in firms that pay payroll taxes. This is not the latest official definition of informality from the International Labour Organization (ILO), but it is a traditional institutionalist definition of informality, and is the most attractive one given the nature of our data.

22 This segment of the market is large, and furthermore some of the job creation observed in PILA may result from the formalization of previously informal jobs.
} 
than 186,000 firms with at least two employees, giving an average total of nearly 6.1 million formal workers observed on a monthly basis over the study period, equivalent to $57 \%$ of all employment. The annex presents some characteristics of firms. For example, the average firm has 33 employees, of whom $60 \%$ are male and around $61 \%$ earn the minimum wage; $61 \%$ of firms are small, with less than 20 employees; and nearly $14 \%$ of firms are medium-sized, with more than 20 and fewer than 100 employees.

Table 1

Summary statistics

\begin{tabular}{|c|c|c|c|c|c|}
\hline Variable & Observations & Mean & $\begin{array}{l}\text { Standard } \\
\text { deviation }\end{array}$ & Minimum & Maximum \\
\hline Formal workers / working population ${ }^{\mathrm{a}}$ & 1725 & 0.48 & 0.08 & 0.27 & 0.59 \\
\hline Salaried formal workers / working population ${ }^{\mathrm{a}}$ & 1725 & 0.40 & 0.07 & 0.20 & 0.51 \\
\hline Salaried formal workers / labour force ${ }^{\mathrm{a}}$ & 1725 & 35.13 & 6.66 & 17.28 & 45.51 \\
\hline Salaried formal workers / working-age population ${ }^{\mathrm{a}}$ & 1725 & 23.39 & 5.24 & 10.52 & 31.41 \\
\hline Hiring rate & 1725 & 9.22 & 2.57 & 3.02 & 24.47 \\
\hline Separation rate & 1725 & 8.47 & 2.44 & 2.18 & 23.13 \\
\hline Job creation rate & 1725 & 5.57 & 2.08 & 2.11 & 23.16 \\
\hline Job destruction rate & 1725 & 4.81 & 1.9 & 1.4 & 21.74 \\
\hline Worker reallocation rate & 1725 & 17.68 & 4.48 & 6.48 & 33.96 \\
\hline Job reallocation rate & 1725 & 10.37 & 3.32 & 3.82 & 27.66 \\
\hline Churn rate & 1725 & 7.31 & 2.59 & 0.67 & 15.98 \\
\hline Real hourly wage rate (pesos) & 1725 & 4221 & 638 & 2771 & 8162 \\
\hline Proportion of working-age population with tertiary education & 1725 & 0.25 & 0.06 & 0.13 & 0.42 \\
\hline Proportion of private sector firms & 1725 & 0.97 & 0.02 & 0.88 & 0.99 \\
\hline Employees' average age & 1725 & 37.41 & 0.81 & 35.1 & 39.61 \\
\hline Employees' average age & 1725 & 1306 & 330 & 97 & 1569 \\
\hline Proportion of male employees & 1725 & 0.63 & 0.03 & 0.55 & 0.69 \\
\hline Department-level labour demand & 1725 & 0.01 & 0.02 & -0.05 & 0.06 \\
\hline GDP per capita & 1725 & 5675 & 188 & 5313 & 6152 \\
\hline Employers' costs (firms) (proportion of mean wages) & 1725 & 0.53 & 0.05 & 0.42 & 0.56 \\
\hline HP filter quarterly GDP & 1725 & -357 & 1112 & -2815 & 1599 \\
\hline Departmental GDP growth & 1725 & 4.31 & 4.58 & -6.37 & 25.18 \\
\hline
\end{tabular}

Source: Prepared by the authors.

a Weighted averages, taking the contributions of each metropolitan area to total employment as weights.

During the period studied, the formal wage employment rate averaged $35 \%$, this being the proportion of the labour force with a formal wage-paying job. The formal-salaried occupation rate, or proportion of the working-age population with a formal wage-paying job, was $23.4 \%$. Overall, the proportion of the workforce with a formal job (formality rate) was $48 \%$. The most select group in the working population are employees with a formal wage-paying job, who accounted for $40 \%$ of the total during the study period. It is worth mentioning some other characteristics of the estimation sample of our regression. For example, the average departmental growth rate during the period was $4.31 \%$, the average employee age was 33.3 and the average hourly wage rate in metropolitan areas during the period studied was 4,221 thousands of Colombian pesos in 2008 values.

We analyse three fluidity measures, namely WR, JR and CR, and two different outcomes, the formal wage employment rate and the formal-salaried occupation rate. We estimate each of the equations using the ordinary least squares (OLS) and instrumental variables (IV) methodology (see table 2). In the case of IV, we use several instruments selected from those described in the previous section. For each regression, we choose the combination of instruments that has the strongest correlation with the endogenous variables; in addition, we run overidentifying restrictions tests with each set of instruments and make sure the hypothesis of the instrument being valid is not rejected. In general, the sets of instruments used are similar for all equations. 


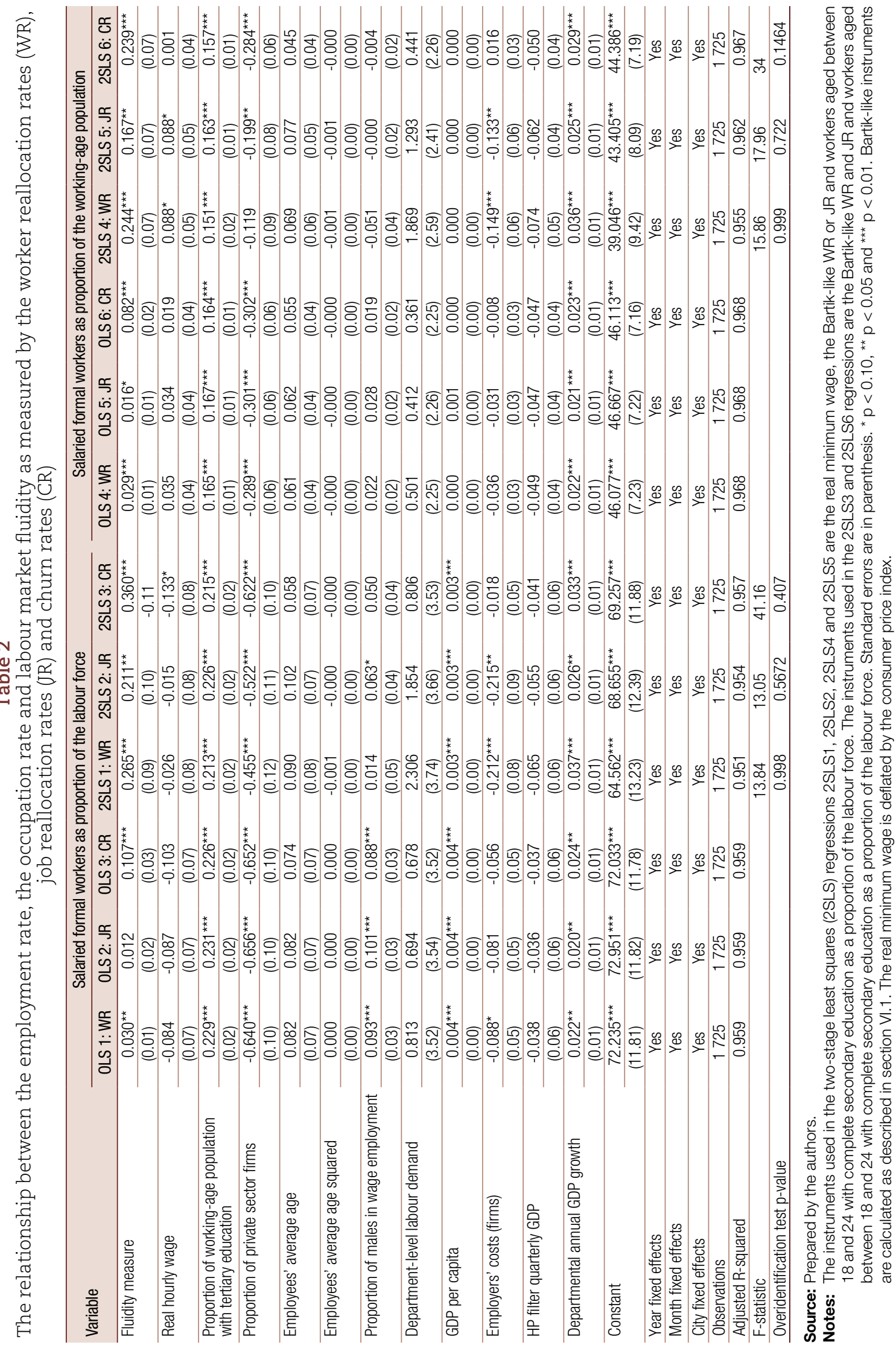


The unit of observation in all the models presented here are labour markets, which we define as Colombian metropolitan areas. We were able to collect all the information needed to estimate equation (1) for the main 23 Colombian metropolitan areas for the period between October 2008 and December 2014. In general, the fit of the regressions is high in all regressions with R-squared above $90 \%$. We include metropolitan area fixed effects, month fixed effects and year fixed effects in all regressions. All these fixed effects explain a large portion of the variation of our dependent variables. The control variables have a consistent sign and significance throughout most of the specifications we estimate. For all our dependent variables, per capita GDP and the proportion of the working-age population with tertiary education correlate positively and significantly with each of these labour indices. As for employment rates, the percentage of private firms correlates negatively and significantly with this labour index. In other words, a labour market where the public sector represents a large share of overall employment has higher employment rates. For this same labour index, we observe a significant and positive correlation with the real GDP growth rate by department.

The worker reallocation rate (WR): The OLS estimations show that the WR has a positive effect on the formal wage employment and occupation rates. The magnitudes of these effects are quite small: an increase of 1 percentage point in the WR increases the formal-salaried employment rate and the formal-salaried occupation rate by 0.030 and 0.029 percentage points, respectively. Regarding the IV results, we find a positive and significant relationship between the WR and the two outcomes. The magnitudes of these relationships are substantially larger than with the OLS: an increase of 1 percentage point in the WR increases the salaried-formal employment and occupation rates by 0.26 and 0.24 percentage points, respectively. These results are in line with what is found for the United States labour market in Davis and Haltiwanger (2014), corroborating a plausible positive causal influence of WR on the employment rate.

The job reallocation rate (JR): The OLS estimations show a positive effect of the JR on formal-salaried employment and occupation rates, with small magnitudes in both cases and a significant effect only for the case of formal-salaried occupation rate. Regarding the IV results, we find a positive and significant plausible causal effect of the JR on both outcomes. The magnitudes of these effects are larger than the ones obtained with the OLS estimation. The effect of a 1 percentage point increase in the JR is an increase of 0.21 and 0.17 percentage points in the formal-salaried employment and occupation rates, respectively. This result contrasts with the negative correlations between the JR and net employment growth found in Davis, Haltiwanger and Schuh (1996). Nevertheless, the evidence for a countercyclical JR is based on unconditional correlations. Our results are in line with Davis and Haltiwanger (2014), who find a plausible positive causal influence of the JR on the employment rate; as in our findings, the JR has a smaller effect than the WR.

Churn Rate (CR): The OLS estimations show that the CR has a positive and significant relationship with both labour market indices. The magnitude of these correlations is small; nevertheless, it is larger than those estimated using OLS for the previous cases of the WR and the JR. With an increase of 1 percentage point in the $\mathrm{CR}$, the formal wage employment and occupation rates rise by 0.11 and 0.08 percentage points, respectively. As regards the IV estimations, as before, the magnitudes of the plausible causal effects of the CR on our outcomes are substantially higher. With an increase of 1 percentage point in the $\mathrm{CR}$, the formal-salaried employment and occupation rates rise by 0.36 and 0.24 percentage points, respectively.

General overview of the results: As explained in section III, from the point of view of equilibrium unemployment theory (Pissarides, 2000), increases in the WR and the CR would be expected to improve labour market performance. Furthermore, from the theoretical framework outlined in Shimer (2001) and Davis and Haltiwanger (2014), increases in all fluidity measures would be expected to improve both our labour market indices. These two studies propose theoretical channels through which fluidity might cause improvements in labour market performance. Shimer (2001) argues that firms find it profitable to create 
jobs in more fluid and younger labour markets, where new employees are cheaper to recruit. Davis and Haltiwanger (2014) propose that workers receive more frequent job offers in fluid labour markets and spells of unemployment are shorter, preventing a costly loss of human capital. These channels also justify positive effects from the WR, CR and JR on the performance of labour markets (Davis and Haltiwanger, 2014).

Our OLS estimations show a positive and almost always significant correlation between all fluidity measures and the labour market indices. The IV estimations show a plausible significant causal effect for all fluidity measures on the labour market indices, and one that is substantially higher than that implied by the OLS regressions. The OLS coefficients are underestimated, then, because unobserved time-varying factors correlate negatively with fluidity measures. Our results are robust to modifications in the set of instruments and changes in the sample considered. ${ }^{23}$

The magnitudes of the effects that the WR, JR and CR have on the labour indices are quite similar; nevertheless, the JR has a smaller effect on formal wage employment and occupation than either the WR or the CR. The CR has the largest effect on employment. These patterns are in line with the theoretical framework of equilibrium unemployment theory, which emphasizes the role of worker flows (especially job-to-job transitions) on the reduction of the equilibrium rate of unemployment. In a general version of these search models, more dynamic job flows are a consequence of enhanced worker flow dynamics resulting from reductions in on-the-job search costs. Specifically, a given increase in worker flows (resulting from job-to-job transitions) will increase job creation and reduce job destruction; thus, the increase in job flows resulting from increased job creation will be partially offset by reduced job destruction. Theoretically, therefore, the effect of job flows on unemployment should be smaller because the greater job flows resulting from a given increase in worker flows are partially offset by lower job destruction. While the $\mathrm{JR}$ is expected to have a smaller effect than the WR, though, search models predict positive effects for the JR in reducing the equilibrium unemployment rate, for the simple reason that job flows are a component of worker flows.

The size of the informal urban labour market in Colombia is considerable. Nevertheless, formal workers were nearly $51 \%$ of the urban occupied population ${ }^{24}$ and formal wage workers more than $43 \%$ of the urban occupied population in 2016. With our data, it is not possible to compute fluidity measures for informal workers. It seems likely that most worker and job dynamics arise in the formal labour market, since informal jobs and workers belong to small firms or are self-employed individuals. ${ }^{25}$ Nevertheless, there is evidence for similar economies in the region which shows that own-account workers present high annual transition rates, especially from self-employed to employee status (Gluzmann, Jaume and Gasparini, 2012); these dynamics can only be partially captured by our fluidity measures, for instance via the creation of formal employment. That is a limitation of this study, since, as mentioned before, we can only compute fluidity measures for the formal labour market. Even though we do not observe informal labour markets flows, the indications are that informal worker and job dynamics are largely linked to job creation and hiring in the formal market, since the reduction in the Colombian informality rate observed in recent years is partly explained by the formalization of firms and jobs as a result of favourable labour market policies (Morales and Medina, 2017; Fernández and Villar, 2017). To summarize, even though we cannot observe the job and worker dynamics of informal workers, we are confident that we can say something meaningful about a large part of the labour market.

\footnotetext{
${ }^{23}$ As a robustness check, we estimated all IV regressions with the minimum wage excluded from the set of instruments. For formal wage employment, a 1 percentage point increase in the WR, JR and CR increases this rate by $0.271,0.188$ and 0.360 percentage points, respectively. For the formal wage occupation rate, a 1 percentage point increase in the WR, JR and CR increases this rate by $0.24,0.10$ and 0.24 percentage points, respectively. In all cases, the coefficients are statistically significant. As an additional robustness check, the starting point of the sample used for all the regressions was moved backwards and forward by one and two months, without any major change in the results.

24 This rate is computed using the International Labour Organization (ILO) definition of informality, which covers non-professional informal workers in firms with five employees or fewer.

25 The proportion of all fluidity explained by very small firms is tiny. Firms with two to five employees represent only $1.09 \%$ of total job flows, $5.87 \%$ of total worker flows and $3.57 \%$ of churn flows.
} 
In a recent paper, Flórez and others (2018) compare fluidity measures between the United States and Colombia. Their analysis reveals differences between the two labour markets; for instance, they find that the quarterly churn rate of the formal labour market is almost twice as great in the United States as in Colombia. ${ }^{26}$ This comparison should be treated with caution given the differences in the composition of the two economies' formal and informal markets and the fact that measurements of labour flows in the United States change depending upon the source (Flórez and others, 2017). Nevertheless, given the characteristics of the two labour markets, there are many reasons to expect that of the United States to be more fluid than Colombia's. The previous literature shows that employment protection and rigid labour market institutions play an important role in reducing labour market dynamism (Blanchard and Portugal, 2001). Colombia has high levels of employment protection, with 4.5 weeks' maternity leave and a number of laws governing wrongful dismissal and termination costs (Cardona-Sosa and others, 2018). ${ }^{27}$ In addition, before the tax reform of 2013, Colombia had one of the highest levels of payroll taxes in the Latin American region, with employer and employee payroll taxes accounting for $60 \%$ of wages. Some of these institutions may add rigidity to the market.

Recent policies have probably helped to increase fluidity and, as described in section $\mathrm{V}$, the labour market became substantially more dynamic after 2010. Recently implemented policies include a sizeable reduction in payroll taxes in 2013 and a number of payroll tax subsidies for young employees and new formal firms (the First Job Act, implemented in 2010). There is evidence that these policies have helped to boost formal employment (Morales and Medina, 2017; Fernández and Villar, 2017).

Lastly, we provide evidence of a plausible causal relationship between fluidity and enhanced labour market performance in terms of employment and occupation. This evidence should be interpreted with caution, however, as we only analyse two of many possible outcomes which might be influenced by labour market fluidity. As mentioned in section III, the literature has identified unwelcome aspects of labour market fluidity, many of them related to job instability. From the evidence in the literature, it seems that job instability is bad for workers and for firms, with the suggestion that there might be a positive relationship between seniority and a firm's productivity (Auer, Berg and Coulibaly, 2005); larger worker and job flows are expected to reduce average employment tenure in the economy.

\section{Conclusions}

This paper analyses the fluidity of the Colombian formal labour market and the relationship between measures of fluidity and some formal labour market outcomes, particularly employment rates and occupation rates for salaried-formal workers. Recent empirical work focusing on the United States economy suggests that fluidity has a positive influence on labour market performance (Davis and Haltiwanger, 2014; Molloy and others, 2016; Shimer, 2001). In addition, recent theoretical developments (search models of equilibrium unemployment) predict that factors which reduce search costs and therefore increase fluidity will lower the equilibrium rate of unemployment. Our work contributes to the empirical literature by estimating the effects of fluidity on formal labour market performance using information on all economic sectors, not only manufacturing. In addition, to the best of our knowledge, there is no other study of the impact of fluidity on labour market performance in a developing economy.

\footnotetext{
26 They reach this conclusion using quarterly churn rates computed from PILA in the case of Colombia, while in the case of the United States they use the quarterly churn rate derived by the Census Bureau from the Longitudinal Employer-Household Dynamics survey. The comparison period was from 2009 to 2016.

27 Unjustified layoffs are expensive in Colombia, with firms having to pay 20 days' wages per year worked. This policy is similar to that of Portugal, one of the countries with the highest termination costs. In 2015, Colombia ranked 29, Portugal 13 and the United States 69 in the Organization for Economic Cooperation and Development (OECD) index of protection for permanent workers, out of 71 countries for which the index could be calculated.
} 
We analyse the standard fluidity measures from October 2008 to December 2014. We find a strong upward trend from 2009 in all three fluidity measures studied in this paper. This is a period in which unemployment fell remarkably. By using econometric models, we show evidence of a consistent, sizeable and plausible causal effect of fluidity measures on both our labour market outcomes. Using simple OLS models, we find almost all fluidity measures to have a positive and significant correlation with formal-salaried employment and occupation rates; nevertheless, the magnitudes of these correlations are small. When an instrumental variable regression approach is used, all the fluidity measures are found to have a positive and significant effect on labour market outcomes, and the magnitudes of the coefficients are substantially higher.

We find that an increase in all our fluidity measures causes increases in salaried-formal employment rates and occupation rates. The magnitudes of the effects are relatively similar for each outcome. An increase of 1 percentage point in any of the fluidity measures causes an increase in formal-employment rates of between 0.21 and 0.36 percentage points in formal employment rates, while an increase of 1 percentage point in the JR, WR or CR causes an increase in formal occupation rates of between 0.17 and 0.24 percentage points. The JR is the variable with the smallest impact, while the CR is the one with the highest impact when it comes to employment rates; this is in line with the predictions of the theoretical framework for equilibrium unemployment.

According to our findings, more fluid labour markets have been beneficial for the Colombian formal labour market during recent years, with the good labour market performance observed between 2009 and 2014 being at least partially the result of greater fluidity. The literature on labour flows usually argues for a positive relationship between fluidity and labour market flexibility (Davis and Haltiwanger, 2014; Molloy and others, 2016). The evidence we present in this paper sheds light on the plausible beneficial effects of policies pursuing greater flexibility. Our conclusions are relevant for a broader understanding of the formal labour market in developing countries; we provide evidence that policies pursuing greater fluidity and flexibility are likely to boost formal employment. Nevertheless, this statement needs to be treated with caution in the light of previous literature on the effects of labour policies in developing countries. The conclusion from a meta-analysis of the subject presented in a 2012 World Bank report (World Bank, 2012) is that both overregulation and underregulation in labour markets reduce firms' productivity and job creation. The report argues that the negative effects of most standard labour regulations are subtle or unknown.

Our findings are relevant to the analysis of current labour markets in the Latin American region and likewise in other developing economies where changes in labour policies have been implemented recently. Some of these policy changes are expected to increase flexibility. In Mexico, for instance, the labour policy reform implemented in 2012 introduced innovative and more flexible labour contracts. In Colombia, the 2012 tax reform reduced payroll taxes, which has promoted the creation of formal jobs (Morales and Medina, 2016). In Ecuador, the labour reform implemented in 2016 introduced new subsidized contracts for young workers, a more flexible conception of working shifts and unpaid leave of absence for childcare to supplement normal maternity leave. Some other labour reforms, such as Chile's, which grants rights to unions, are expected to reduce flexibility. In this paper, we identify a plausible causal relationship between fluidity and formal labour market performance that can be used as a yardstick for predicting the possible consequences of all these policies implemented in developing economies. We cannot say much about informal labour markets, and that is a limitation of this study, considering that the informal sector of the Colombian economy is substantial. Further research on the construction of proxy measures of labour flows for the informal market is needed; to the best of our knowledge, not a single study has been able to analyse the labour market fluidity of the informal sector in any country. This lack of knowledge about labour market dynamics is due to the impossibility of observing the informal market by means of traditional data sources. 


\section{Bibliography}

Akerlof, G. A. and others (1988), "Job switching and job satisfaction in the U.S. labor market", Brookings Papers on Economic Activity, No. 2, Washington, D.C., Brookings Institution Press.

Auer, P., J. Berg and I. Coulibaly (2005), “¿El trabajo estable mejora la productividad?”, International Labour Review, vol. 124, No. 3, Geneva, International Labour Organization (ILO).

Autor, D. H., J. J. Donohue III and S. J. Schwab (2006), "The costs of wrongful-discharge laws", The Review of Economics and Statistics, vol. 88, No. 2, Cambridge, The MIT Press.

Autor, D. H. and M. G. Duggan (2003), "The rise in the disability rolls and the decline in unemployment", The Quarterly Journal of Economics, vol. 118, No. 1, Oxford, Oxford University Press.

Autor, D. H., W. R. Kerr and A. D. Kugler (2007), "Does employment protection reduce productivity? Evidence form US states", The Economic Journal, vol. 117, No. 521, Wiley.

Bartik, T. J. (1991), Who Benefits from State and Local Economic Development Policies?, Kalamazoo, Upjohn Press.

Bjelland, M. and others (2011), "Employer-to-employer flows in the United States: estimates using linked employeremployee data", Journal of Business \& Economic Statistics, vol. 29, No. 4, Abingdon, Taylor \& Francis.

Blanchard, O. and L. Katz (1992), "Regional evolutions", Brookings Papers on Economic Activity, No. 1, Washington, D.C., The Brookings Institution.

Blanchard, O. and P. Portugal (2001), "What hides behind an unemployment rate: comparing Portuguese and U.S. labor markets", The American Economic Review, vol. 91, No. 1, Nashville, American Economic Association.

Boeri, T. and J. F. Jimeno (2005), "The effects of employment protection: learning from variable enforcement", European Economic Review, vol. 49, No. 8, Amsterdam, Elsevier.

Bound, J. and H. J. Holzer (2000), "Demand shifts, population adjustments, and labor market outcomes during the 1980s", Journal of Labor Economics, vol. 18, No. 1, Chicago, The University of Chicago Press.

Burgess, S., J. Lane and D. Stevens (2000), "Job flows, worker flows, and churning", Journal of Labor Economics, vol. 18, No. 3, Chicago, The University of Chicago Press.

Cardona-Sosa, L., Flórez, L. A., Morales, L. F., and Banco de la República (2018), "How does the Household Labour Supply Respond to the Unemployment of the Household Head?", LABOUR, vol. 32, No. 4.

Davis, S. J., J. Faberman and J. C. Haltiwanger (2012), "Labor market flows in the cross section and over time", Journal of Monetary Economics, vol. 59, No. 1, Amsterdam, Elsevier.

Davis, S. J. and J. Haltiwanger (2014), "Labor market fluidity and economic performance", NBER Working Paper, No. 20479, Cambridge, National Bureau of Economic Research.

(1999), "Gross job flows", Handbook of Labor Economics, O. Ashenfelter and D. Card (eds.), vol. 3, Amsterdam, Elsevier.

(1992), "Gross job creation, gross job destruction, and employment reallocation", The Quarterly Journal of Economics, vol. 107, No. 3, Oxford, Oxford University Press.

Davis, S. J., J. C. Haltiwanger and S. Schuh (1996), Job Creation and Destruction, Cambridge, The MIT Press.

Davis, S. J. and T. M. Von Wachter (2011), "Recessions and the cost of job loss", NBER Working Paper, No. 17638, Cambridge, National Bureau of Economic Research (NBER).

Decker, R. and others (2014), "The role of entrepreneurship in US job creation and economic dynamism", The Journal of Economic Perspectives, vol. 28, No. 3, Nashville, American Economic Association.

Fernández, C. and L. Villar (2017), "The impact of lowering the payroll tax on informality in Colombia", Economia, vol. 18, No. 1, Washington, D.C., Brookings Institution Press.

Flórez, L. A. and others (2018), "Labour flows across firm's size, economic sectors and wages: evidence from employer-employee linked panel", Borradores de Economía, No. 1013, Bogotá, Bank of the Republic.

Gluzmann, P., D. Jaume and L. Gasparini (2012), "Decisiones laborales en América Latina: el caso de los emprendedores. Un estudio sobre la base de encuestas de hogares", Working Paper, No. 137, Center for Distributive, Labor, and Social Studies (CEDLAS).

Gómez-Salvador, R., J. Messina and G. Vallanti (2004), "Gross job flows and institutions in Europe", Labour Economics, vol. 11, No. 4, Amsterdam, Elsevier.

Hyatt, H. R. and J. R. Spletzer (2013), "The recent decline in employment dynamics", IZA Journal of Labor Economics, vol. 2, No. 1, Springer.

Morales, L. F., and D. Medina (2016), "Labor fluidity and performance of labor outcomes in Colombia: evidence from employer-employee linked panel”, Borradores de Economía, No. 926, Bogotá, Bank of the Republic. 
Melo, L. and C. Ballesteros (2014), "Impacto de los factores externos sobre la creación y destrucción de empleo en el sector manufacturero colombiano", Lecturas de Economía, No. 81, Medellín, University of Antioquia.

_ (2013), "Creación, destrucción y reasignación del empleo en el sector manufacturero", Revista de Economía Institucional, vol. 15, No. 28, Bogotá, Externado University of Colombia.

Molloy, R. and others (2016), "Understanding declining fluidity in the US labor market", Brookings Papers on Economic Activity, Washington, D.C., The Brookings Institution.

Morales, L. F. and J. Lobo (2017), “Estimating Vacancies from Firms' Hiring Behavior: The Case of a Developing Economy", Borradores de Economía, No. 1017, Bogotá, Bank of the Republic.

Morales, L. F. and C. Medina (2017), "Assessing the effect of payroll taxes on formal employment: the case of the 2012 tax reform in Colombia", Economia, vol. 18, No. 1, Washington, D.C., Brookings Institution Press. (2016), "Assessing the effect of payroll taxes on formal employment: the case of the 2012 tax reform in Colombia", Borradores de Economía, No. 971, Bogotá, Bank of the Republic.

Pagés, C., G. Pierre and S. Scarpetta (2009), Job Creation in Latin America and the Caribbean. Recent Trends and Policy Challenges, Washington, D.C., World Bank/Palgrave Macmillan.

Pissarides, C. (2000), Equilibrium Unemployment Theory, Cambridge, The MIT Press.

Shimer, R. (2001), "The impact of young workers on the aggregate labor market", The Quarterly Journal of Economics, vol. 116, No. 3, Oxford, Oxford University Press.

World Bank (2012), World Development Report 2013: Jobs, Washington, D.C.

\section{Annex A1}

Table A1.1

Summary statistics on firms

\begin{tabular}{lccc}
\hline Variable & Observations & Mean & Standard deviation \\
\hline Employment & 13977725 & 32.65387 & 263.3392 \\
\hline Private firms & 13977725 & 0.972648 & 0.163108 \\
\hline Average wage as proportion of minimum wage & 13958019 & 1.554001 & 1.199409 \\
\hline Proportion of wages less than or equal to the minimum wage & 13977725 & 60.98038 & 39.64137 \\
\hline Proportion of men & 13977725 & 59.72614 & 31.84601 \\
\hline Proportion of firms with 20 employees or fewer & 13977725 & 0.815355 & 0.3880093 \\
\hline Proportion of firms with more than 20 and fewer than 100 employees & 13977725 & 0.138829 & 0.3457676 \\
\hline Proportion of firms with more than 100 employees & 13977725 & 0.045816 & 0.2090867 \\
\hline
\end{tabular}

Sourced: Prepared by the authors. 